\title{
RA?EGA
}

O ESPACYO GEOGRÁFICO EM ANÁLISE

\section{APTIDÃO URBANA AOS INSTRUMENTOS DO ESTATUTO DA CIDADE: PERSPECTIVAS METODOLÓGICAS}

\section{URBAN APTITUDE TO THE CITY STATUTE INSTRUMENTS: METHODOLOGICAL PERSPECTIVES}

\author{
Mirna Luiza Cortopassi Lobo \\ Programa de Pós-Graduação em Geografia \\ Universidade Federal do Paraná (UFPR) \\ Curitiba, $P R$ \\ e-mail:mirna.lobo@caubr.gov.br \\ Ana Maria Muratori \\ Programa de Pós-Graduação em Geografia \\ Universidade Federal do Paraná (UFPR) \\ Curitiba, $P R$ \\ e-mail: amuratori@uol.com.br
}

Recebido em: 28/05/2014

Aceito em: 06/02/2015

\section{Resumo}

A Lei Federal 10.257/01, conhecida como Estatuto da Cidade, cuja função principal é regulamentar os artigos 182 e 183 da Constituição Federal de 1988, instituiu a obrigatoriedade da elaboração de planos diretores para municípios com mais de 20.000 habitantes e municípios com situações específicas como os que integram as regiões metropolitanas ou aqueles de interesse turístico. Simultaneamente, o Estatuto da Cidade legitimou instrumentos criados a partir da década de $1950 \mathrm{em}$ várias cidades brasileiras, quando a questão urbana passou a ser vista como um problema social a ser equacionado no âmbito municipal, direcionado e gerenciado pelos planos diretores, monitorado por novos instrumentos complementares aos préexistentes. No entanto, a implementação desses instrumentos integrados às leis dos planos diretores municipais, passa pelo gargalo da seleção da maior aptidão de cada setor urbano, ou outra unidade territorial da cidade, para a implantação de cada instrumento ou de um conjunto de instrumentos. Nesse contexto, o presente artigo visa colaborar, discutindo o estabelecimento de indicadores que, relacionados a cada instrumento, possam identificar tais aptidões, através de análises simplificadas das características das cidades. É importante destacar que essa metodologia está voltada principalmente a cidades de porte médio, que se posicionam aquém das metrópoles, quanto a demandas de estudos mais apurados, face às características das variáveis que se sobrepõem em sua estrutura urbana. Outro aspecto importante que vale salientar é que a aplicação dos instrumentos baseados nos indicadores não garante por si só os resultados pretendidos, 


\title{
APTIDÃO URBANA AOS INSTRUMENTOS DO ESTATUTO DA CIDADE: PERSPECTIVAS METODOLÓGICAS
}

dependendo de outras variáveis de cunho político e da visão dos atores sociais. São alternativas a serem submetidas ao processo decisório.

Palavras-chave: Indicadores, Instrumentos do Estatuto da Cidade.

\begin{abstract}
The Federal Law 10.257/01, known as the City Statute, whose main function was to regulate Articles 182 and 183 of the 1988 Federal Constitution, has established the obligation to draw up master plans for municipalities with over 20,000 inhabitants, as well as municipalities with specific situations such as those comprising metropolitan areas or those with touristic interest. Simultaneously, the City Statute legitimized instruments created during the decade of 1950, in several Brazilian cities, when the urban question started to be seen as a social problem to be solved at the municipal level, directed and managed by the master plans. The City Statute has also instituted new complementary instruments for the existing ones. However, the implementation of these instruments, which have been integrated to the laws of municipal master plans, pass through the bottleneck of the selection of each urban district vocation, or other administrative unit of the city, for the implementation of each instrument or a set of instruments. This paper aims to cooperate on this direction, through the establishment of indicators that can identify the vocation of each district for each instrument, through simplified analysis of the city characteristics. This methodology is focused mainly on mid-size cities, which are positioned below to the metropolis level, which demands more accurate studies, given the characteristics of the variables that overlap in their urban structure. Another important aspect to emphasize is the fact that the application of the instruments based upon these indicators doesn't ensure the aimed results, depending on other variables of a political nature and sense of social actors. They are alternatives to be submitted to decision process.
\end{abstract}

Keywords: Indicators, Instruments of City Statute.

\section{INTRODUÇÃO}

As leis municipais que instituem os Planos Diretores Municipais estabelecem os princípios básicos e as diretrizes para sua implantação. Legislam também sobre os instrumentos de planejamento, os instrumentos jurídicos, urbanísticos e de regularização fundiária. Adicionalmente, regulamentam os instrumentos tributários e financeiros, os instrumentos jurídico-administrativos a serem considerados pela política urbana, estabelecidos pela Lei Federal no 10.257/2001, o Estatuto da Cidade, assim como os demais instrumentos de desenvolvimento, não mencionados na Lei Nacional, desde que atendam ao disposto no Plano Diretor. 


\section{APTIDÃO URBANA AOS INSTRUMENTOS DO ESTATUTO DA CIDADE: PERSPECTIVAS METODOLÓGICAS}

Os instrumentos da política urbana estabelecidos pelo Estatuto da Cidade, são os seguintes:
A. Parcelamento do Solo, da Edificação ou da Utilização Compulsórios;
B. IPTU Progressivo no Tempo;
C. Desapropriação com Títulos da Dívida Pública;
D. Usucapião Especial de Imóvel Urbano;
E. Concessão de Uso Especial para Fins de Moradia;
F. Direito de Superfície;
G. Direito de Preempção;
H. Outorga Onerosa do Direito de Construir;
I. Transferência de Potencial Construtivo;
J. Zonas Especiais de Interesse Social;
K. Estudo de Impacto de Vizinhança.

É preciso salientar que a metodologia discutida no presente artigo não se aplica ao instrumento Operações Urbanas Consorciadas pela natureza do mesmo ser localizada e as variáveis a serem consideradas muito distintas.

Os instrumentos podem ser absorvidos total ou parcialmente pelos Planos Diretores, sendo opcionalmente regulamentados em legislação específica e, posteriormente, aplicados no prazo máximo definido em lei. Conforme os resultados obtidos na Pesquisa Rede Nacional de Avaliação dos Planos Diretores Participativos (2010), a incorporação dos instrumentos nos Planos Diretores Municipais se dá de diferentes formas, dentro do cenário de análise dos planos diretores:

\footnotetext{
Muitos Planos apenas transcrevem trechos do Estatuto, outros incorporam os instrumentos sem avaliar sua pertinência ao território e à capacidade de gestão do município, outros, ainda, incorporam alguns fragmentos de conceitos e ideias do Estatuto de modo desarticulado com o próprio plano urbanístico. (SANTOS JUNIOR; MONTANDON, 2011, p.33)
}

Cada instrumento constante do Plano Diretor, após regulamentado, é passível de ser aplicado a todos os setores urbanos ou apenas a áreas específicas. O caráter genérico da Lei, quanto à definição de "onde" aplicar os instrumentos é pertinente, pois não circunscreve sua aplicação a determinadas áreas e tem como pano de fundo o cumprimento da função social da cidade e da propriedade para toda a cidade. 


\title{
MURATORI, A.M.; LOBO, M.L.C. \\ APTIDÃO URBANA AOS INSTRUMENTOS DO ESTATUTO DA CIDADE: PERSPECTIVAS METODOLÓGICAS
}

Essa definição se torna crucial para a efetiva operacionalização dos instrumentos na gestão urbana. No entanto, faltam critérios para a sua priorização e seleção dos locais onde aplicá-los. De acordo com Honorato (2012, p.1):

O Estatuto da Cidade ainda busca impor-se moralmente à edilidade para a severa implantação de seus instrumentos de regulação da ocupação e do uso do solo, por meios que garantam à sociedade esclarecimento sobre seu direito de participação e de controle sobre as intervenções físicas, quando da real necessidade e da priorização quanto à locação territorial e à boa qualidade para a ordem urbana

Nesse contexto, o presente artigo visa contribuir para essa seleção através da definição de critérios locacionais, contribuindo para a real aplicabilidade dos instrumentos e indicando um caminho para a administração pública tomar a decisão quanto a gestão do território.

\section{JUSTIFICATIVA}

Existe uma lacuna para se estabelecer critérios de aplicabilidade desses instrumentos a partir do passivo social que gerou a ocupação do espaço urbano, cujas características díspares requerem análises mais aprofundadas para estabelecer sua adequação aos distintos setores urbanos. De acordo com Santos Junior e Montandon (2011, p.36),

\begin{abstract}
Podem ser diversas razões que justificam a insuficiente e inadequada demarcação territorial de diretrizes e instrumentos nos Planos Diretores: leitura técnica e comunitária mal elaborada, poucos recursos técnicos e humanos para a elaboração de mapas e demais peças técnicas, inexistência ou precariedade de cadastros e de informações básicas sobre 0 território, reduzido tempo para o processo de elaboração do Plano Diretor, descaso ou desinteresse dos gestores e do legislativo com o processo de elaboração ou aprovação do Plano Diretor, entre outros motivos.
\end{abstract}

É portanto necessário identificar a aptidão dos setores urbanos em correlação com os objetivos de cada instrumento para reverter o que constatam Pereira da Silva e Trípoli Magalhães (2013, p. 1): "O que se percebe na cidade é a tendência da criação de partes qualificadas versus territórios desprovidos de qualquer estrutura", ou seja, ampliar para toda a cidade, a aplicabilidade dos instrumentos.

Esta circunstância vem de encontro à assertiva de Ultramari e Rezende (2006, p.25): "Os Planos Diretores parecem repetir instrumentos já disponibilizados 


\title{
MURATORI, A.M.; LOBO, M.L.C. \\ APTIDÃO URBANA AOS INSTRUMENTOS DO ESTATUTO DA CIDADE: PERSPECTIVAS METODOLÓGICAS
}

pela lei às administrações dos municípios e não utilizados". Isto significa que os planos diretores não avançam em relação ao tema, considerando as especificidades locais de cada cidade.

Essas características podem ser estratificadas em indicadores que considerem os aspectos territoriais quanto à ocupação urbana e às intervenções sobre os mesmos que imprimem o caráter de urbanidade ao meio físico.

Portanto, os critérios apresentados a seguir visam à identificação da aptidão dos setores ou outra compartimentação urbana à aplicação prioritária dos instrumentos a serem utilizados pela política urbana municipal, em consonância com as características de cada cidade.

A aptidão dos setores urbanos pode servir de insumo ao processo decisório dos Conselhos Municipais do Plano Diretor que estabelecerão, face às demandas sociais identificadas pela gestão urbanística, adicionalmente, quais serão os prioritários.

No entanto, tais decisões devem passar pelo crivo da sociedade, o que ainda é difícil em nosso meio. Conforme afirma Villaça (2005, p.53):

[...] em termos relativos, os debates públicos em torno do Plano Diretor representaram um avanço democrático muito pequeno. Em primeiro lugar porque, como anteriormente havia pouquíssima participação popular, diante de zero, qualquer crescimento é infinito. Em segundo, porque em termos de pressões políticas sobre os governantes, a da minoria foi enorme e a da maioria foi limitadíssima.

Esses debates públicos devem se estender à aplicação dos instrumentos, mormente por se tratarem de aplicações particularizadas no território, cujo conhecimento tácito é de domínio da população. De fato, conforme França, (2012, p.9):

\begin{abstract}
É preciso que ocorra a mobilização da sociedade, pensando e discutindo sobre os problemas urbanos de forma permanente através dos instrumentos preconizados em Lei e não apenas no momento da discussão do Plano Diretor. A participação popular deve se tornar um costume e cotidiano da sociedade, pois só assim será possível construir uma cidade democrática.
\end{abstract}

A mobilização da sociedade é particularmente importante, principalmente considerando que a aplicação dos instrumentos não é perene e está intrinsicamente 


\section{MURATORI, A.M.; LOBO, M.L.C. \\ APTIDÃO URBANA AOS INSTRUMENTOS DO ESTATUTO DA CIDADE: PERSPECTIVAS METODOLÓGICAS}

relacionada com a dinâmica da evolução urbana, necessitando adequações e redirecionamentos ou substituições temporais.

\section{MATERIAIS E MÉTODOS}

O presente artigo foi elaborado a partir da experiência desenvolvida quanto à análise de vários planos diretores municipais ${ }^{1}$, onde os instrumentos também carecem de definição locacional para sua aplicação e da disponibilidade de informações ali contidas, ou seja, em conjugação com as informações disponíveis, o que poderia ser feito para suprir tal lacuna. Trata-se de abordagem metodológica que utiliza simulações para a comparação entre distintos setores urbanos hipotéticos e os pesos relativos dos indicadores em relação à sua pertinência para aplicação de cada instrumento da política urbana.

Para tanto, foram criados os seguintes indicadores, que passamos a descrever:

a) Índice de Densidade Demográfica Ponderal

A constatação básica da deseconomia ${ }^{2}$ da territorialidade urbana está diretamente relacionada com as densidades demográficas existentes, reflexo das densidades de ocupação do solo e as densidades máximas de urbanização (cenários de ocupação) definidas pela Legislação de Parcelamento e Zoneamento de Uso e Ocupação do Solo.

Denominou-se este indicador Densidade Demográfica Ponderal, pois estabelece a correlação entre a densidade atual e o cenário da densidade futura.

\footnotetext{
${ }^{1}$ Foram analisados os planos de Uberlândia (2010), Umuarama (2005) e São Miguel do Iguaçu (2002), coordenados pela empresa Tese Tecnologia em Sistemas Espaciais Ltda.

${ }^{2}$ Deseconomia - De acordo com o Dicionário Aulete, deseconomia é o fenômeno que se observa quando o crescimento da produção de uma empresa ultrapassa a escala de seus recursos, provocando, em consequência, a elevação dos custos médios". Este conceito aplicado à cidade é entendido como a elevação dos custos médios da infraestrutura urbana em relação ao número de habitantes que a utiliza, no caso representado pela densidade demográfica urbana.
} 


\section{APTIDÃO URBANA AOS INSTRUMENTOS DO ESTATUTO DA CIDADE: PERSPECTIVAS METODOLÓGICAS}

Caso fosse considerada apenas a densidade absoluta dos setores urbanos, poderse-ia cometer o equívoco de induzir alguns adensamentos de forma aleatória à vocação do setor urbano, no contexto da Lei do Plano Diretor. Para tanto, utiliza-se a metodologia que estima a densidade máxima de urbanização (cenário de ocupação) de cada setor urbano, comparando-a com a densidade de ocupação atual, obtendo assim, a Densidade Demográfica Ponderal.

b) Índice de Pavimentação

Quanto ao indicador Índice de Pavimentação a metodologia estabelece a razão entre as áreas pavimentadas e as áreas totais dos setores, excluídos 0 patrimônio público, os equipamentos e áreas verdes e de preservação permanente, aquilatando a proporcionalidade do investimento público quanto ao sistema viário.

c) Índice de Equipamentação Urbana

O indicador Índice de Equipamentação Urbana estabelece a relação entre o número de equipamentos existentes nos setores e a população, constituindo um indicativo quanto ao atendimento da população por estes equipamentos e quanto ao investimento público no setor.

d) Índice de Áreas Institucionais

O indicador Índice de Áreas Institucionais estabelece a presença destas áreas nos distintos setores urbanos, em função da demanda que os mesmos atendem e geram quanto às externalidades de sua função. Trata-se de uma demanda adicional como critério para aplicação de instrumentos de política urbana.

e) Índice de Desconformidade Fundiária

O indicador Índice de Desconformidade Urbana estabelece a relação entre a cidade legal e a cidade irregular ou clandestina, através da comparação entre estas ocupações existentes nos distintos setores. Trata-se de um fator social da maior importância para a definição dos critérios de aplicação de instrumentos pelo poder público, principalmente quanto à delimitação de Zonas Especiais de Interesse Social. 


\section{APTIDÃO URBANA AOS INSTRUMENTOS DO ESTATUTO DA CIDADE: PERSPECTIVAS METODOLÓGICAS}

f) Índice de Vulnerabilidade Urbana

O indicador Índice de Vulnerabilidade Urbana identifica a proporcionalidade das áreas sujeitas a riscos ambientais, como enchentes ou escorregamentos, em relação às áreas totais dos setores. Analisado em conjugação com os demais indicadores como a Densidade Demográfica Ponderal permite identificar aptidões ou não para aplicação de instrumentos como IPTU Progressivo.

A partir dos objetivos dos distintos Instrumentos definidos pelo Estatuto da Cidade são estabelecidas suas correlações com os Indicadores acima descritos e criadas matrizes dos resultados por setores, que identificam a aptidão dos mesmos para a implantação dos instrumentos.

\section{RESULTADOS E DISCUSSÃO}

Os resultados obtidos estabelecem as correlações entre os seis Indicadores criados e os Instrumentos, a partir de sua relação ao objetivo do Instrumento. Quando esta relação for direta, ela é alta. É baixa quando for indireta. Infelizmente os contratos firmados entre os profissionais de planejamento urbano e o governo local não se estendem ao monitoramento da aplicação e da gestão do plano diretor. Estes são de responsabilidade do Conselho da Cidade, quando existe, ou do Conselho do Plano Diretor. Portanto, o presente artigo se restringe a uma abordagem metodológica que, aplicada na prática, deve se constituir em um processo de gestão, e não um instantâneo de uma determinada situação.

Assim sendo, são estabelecidas aprioristicamente, as correlações entre os indicadores e os instrumentos, que retratam somente uma fotografia estática.

\section{a) Densidade Demográfica Ponderal}

Quanto maior a densidade demográfica ponderal, maior a aptidão para a aplicação do instrumento, tendo em vista que se trata de áreas com a ocupação consolidada e onde a otimização do uso do solo possibilitará a redução dos vazios urbanos. 
b) Índice de Pavimentação

Quanto maior o índice, maior a aptidão para a utilização do instrumento, tendo em vista tratar-se de áreas com infraestrutura de pavimentação instalada.

c) Índice de Equipamentação Urbana

Quanto maior o índice, maior a aptidão para a utilização do instrumento, tendo em vista a disponibilidade equipamentos urbanos.

d) Índice de Áreas Institucionais

Quanto maior o índice, maior a aptidão para a utilização do instrumento, tendo em vista a disponibilidade de áreas institucionais para a implantação de equipamentos urbanos. Aqui é importante considerar se as áreas institucionais já estão ocupadas ou não. Caso estejam, permanece também a correlação quanto aos serviços ofertados.

e) Índice de Desconformidade Fundiária

Quanto maior o índice, maior a aptidão para a utilização do instrumento.

f) Índice de Vulnerabilidade Urbana

A relação entre o índice e a aptidão para aplicação do instrumento é inversamente proporcional, portanto quanto maior o índice menor a aptidão ou quanto menor o índice, maior a aptidão para a utilização do instrumento.

Quanto aos instrumentos, os mesmos são analisados em compatibilidade ao estabelecido pelo Estatuto da Cidade, de acordo com seus objetivos ali contidos e descritos a seguir:

\section{A. Parcelamento do Solo, da Edificação ou da Utilização Compulsórios}

Induzir a ocupação de áreas já dotadas de infraestrutura e equipamentos, mais aptas para urbanizar, evitando pressão de expansão horizontal na direção de áreas não servidas de infraestrutura ou frágeis, sob o ponto de vista ambiental. 


\section{B. IPTU Progressivo no Tempo}

Visar o cumprimento da função social da cidade e da propriedade por meio da indução da ocupação das áreas vazias ou subutilizadas, impedindo o processo de retenção especulativa de imóvel urbano, que resulte na sua subutilização ou não utilização.

\section{Desapropriação com Títulos da Dívida Pública}

Dar cumprimento à função social da cidade e da propriedade por meio da indução da ocupação das áreas vazias ou subutilizadas, sancionando o proprietário que à descumprir.

\section{Usucapião Especial de Imóvel Urbano}

Legalizar a permanência de populações moradoras de áreas urbanas ocupadas em desconformidade com a lei, resgatando sua cidadania. Considerando a sua característica legal, a avaliação do instrumento será feita para regularização de ocupações urbanas coletivas, sendo que a legalização de imóveis individuais tem a sua tramitação definida pelo judiciário.

\section{E. Concessão de Uso Especial para Fins de Moradia}

Legalizar a permanência de populações moradoras de áreas urbanas ocupadas em desconformidade com a lei, resgatando sua cidadania. Da mesma forma que o usucapião urbano, considerando a sua característica legal, a avaliação do instrumento será feita para regularização de ocupações urbanas coletivas, sendo que a legalização de imóveis individuais tem a sua tramitação definida pelo poder judiciário.

\section{F. Direito de Superfície}

Separar a propriedade dos terrenos urbanos do direito de edificação, reconhecendo-se que o direito de construir tem um valor em si mesmo, independentemente do valor da propriedade. 


\title{
APTIDÃO URBANA AOS INSTRUMENTOS DO ESTATUTO DA CIDADE: PERSPECTIVAS METODOLÓGICAS
}

\section{G. Direito de Preempção}

Facilitar a aquisição por parte do poder público de áreas de seu interesse, para a realização de projetos específicos.

\section{H. Outorga Onerosa do Direito de Construir}

Separar a propriedade dos terrenos urbanos do direito de edificação, reconhecendo-se que o direito de construir tem um valor em si mesmo, independentemente do valor da propriedade, favorecendo a capacidade do poder público de interferir sobre o mercado imobiliário.

\section{Transferência de Potencial Construtivo}

Possibilitar a implantação de equipamentos urbanos e comunitários; preservar imóveis de interesse histórico, ambiental, paisagístico, social ou cultural; servir a programas de regularização fundiária, urbanização de áreas ocupadas por população de baixa renda e habitação de interesse social, a partir da transferência do potencial construtivo do imóvel.

\section{J. Zonas Especiais de Interesse Social (ZEIS)}

Permitir a inclusão urbana de parcelas da população que se encontram à margem do mercado legal de terras; possibilitar a extensão dos serviços e da infraestrutura urbana nas regiões não atendidas e garantir a qualidade de vida e a equidade social entre as ocupações urbanas.

A despeito de tal objetivo visar a inclusão urbana das habitações de interesse social, há que considerar o que pondera Janot (2012, p.1):

\begin{abstract}
Nada justifica as ocupações de áreas inóspitas e afastadas do núcleo urbano das cidades. Um programa governamental com a envergadura do "Minha Casa Minha Vida" deveria servir como exemplo para nortear a aplicação dos vultosos recursos financeiros em benefício da população e das cidades.
\end{abstract}

Atualmente, a lógica de expansão das cidades é de forma tentacular em função das oportunidades de aquisição de terrenos para os novos conjuntos habitacionais que são implantados sem as infraestruturas dos serviços e 


\section{APTIDÃO URBANA AOS INSTRUMENTOS DO ESTATUTO DA CIDADE: PERSPECTIVAS METODOLÓGICAS}

equipamentos sociais que caracterizam a cidade. Portanto, no caso das ZEIS, a atual política governamental do programa Minha Casa Minha Vida, não deve prescindir de análises singular a aqui contida, através da utilização de indicadores para selecionar o melhor local para sua implantação.

Os objetivos dos instrumentos permitem analisar os indicadores quanto ao grau de relação para sua consecução, através das aptidões de cada bairro ou setor urbano, a partir do investimento social nos mesmos.

\subsection{Geração dos indicadores}

Quanto à criação dos indicadores, a presente abordagem se restringe à disponibilidade usual de informações sobre o território urbano sistematizadas em diagnósticos de Planos Diretores, normalmente advindas dos cadastros técnicos municipais. Têm sua origem na análise informacional contida nos planos mencionados no capítulo 3 deste artigo.

Na medida em que o Sistema de Informações Urbanas for incrementado em cada cidade com informações adicionais, indicadores mais depurados poderão ser criados no sentido de localizar a aplicação dos instrumentos. Por exemplo, na inexistência do mapeamento de toda a infraestrutura urbana, sugere-se a criação do Índice de Pavimentação por bairro, que é menos significativo do que o Índice de Infraestrutura, sem dúvida mais adequado à leitura da aptidão dos setores urbanos para a aplicação do Instrumento do IPTU Progressivo no Tempo.

Com a criação do Cadastro de Logradouros, no Sistema de Informações, com os atributos das distintas infraestruturas em cada segmento dos eixos de vias, este indicador deverá ser substituído e detalhado por quadra, e assim sucessivamente, em função do detalhamento da informação urbana.

\subsubsection{Densidade Demográfica Ponderal}

A Densidade Demográfica Ponderal é obtida a partir do cálculo da Densidade Bruta, utilisando os dados populacionais do Censo do IBGE, aplicados uniformemente a cada setor urbano, divididos pela sua área, cuja delimitação é um nível de agregação de setores censitários. 


\section{APTIDÃO URBANA AOS INSTRUMENTOS DO ESTATUTO DA CIDADE: PERSPECTIVAS METODOLÓGICAS}

Para o cálculo da Densidade Ponderal, é necessário o cálculo das densidades atuais que se obtém aplicando o número de habitantes de cada setor censitário à área líquida dos setores urbanos, que efetivamente são ocupadas pela população. Os cenários das densidades máximas também se referem às áreas líquidas das zonas de uso e ocupação do solo: áreas das quadras contidas nas zonas, eliminado o sistema viário, áreas verdes, patrimônio público e equipamentos. Este critério para quantificação das áreas líquidas para cálculo das densidades é adotado em função das características do sistema viário urbano, principalmente se a cidade possuir grandes avenidas com canteiros centrais.

O indicador de Densidade Ponderal é obtido, através da divisão da densidade atual pela densidade máxima do bairro, seguindo os passos abaixo descritos. Será sempre um índice menor que 01 (um), que indicará o potencial de ocupação de um determinado bairro ou setor urbano. Aqueles setores que tiverem maior potencial de ocupação estarão mais aptos à aplicação dos instrumentos urbanísticos de incentivo à ocupação.

\subsubsection{Mensuração das áreas líquidas urbanas}

É possível sua mensuração excluindo-se o sistema viário, o patrimônio público, os equipamentos, áreas verdes e de preservação permanente. Desta forma obtém-se com mais precisão as áreas efetivas a serem utilizadas para os cenários de ocupação.

No caso de setores onde não existe sistema viário implantado e tão somente as suas diretrizes, deve ser reproduzido o padrão de ocupação existente, respeitadas as diretrizes do sistema viário.

\subsubsection{Definição dos cenários de ocupação}

Para a obtenção do cenário de ocupação urbana são aplicados os parâmetros obtidos a partir da Lei de Parcelamento e Zoneamento de Uso e Ocupação do Solo, que são os seguintes:

- Zoneamento;

- Usos permitidos;

- Áreas dos lotes mínimos por zona; 


\section{APTIDÃO URBANA AOS INSTRUMENTOS DO ESTATUTO DA CIDADE: PERSPECTIVAS METODOLÓGICAS}

- Taxa de ocupação por zona;

- Número máximo de Pavimentos permitidos;

- Coeficiente de aproveitamento.

Estes cenários são aplicados às áreas líquidas obtidas conforme critério descrito anteriormente, utilizando o critério de uso dominante por zona. Para tanto se torna necessário obter:

- Taxas de uso residencial para as distintas zonas, obtidos através do conhecimento tácito dos técnicos municipais:

\begin{tabular}{|c|c|c|c|}
\hline Zona & Taxa (\%) & Zona & Taxa (\%) \\
\hline & & & \\
\hline
\end{tabular}

Quadro 1: Taxa de uso dominante por zona

- Cálculo do número de lotes a partir da área líquida do bairro e da área do lote mínimo por zona. Esta medida é adotada para se criar o cenário com o parcelamento máximo permitido em cada zona urbana;

- Área média domiciliar definida a partir do conhecimento tácito da tipologia construtiva das zonas, aplicadas ao bairro;

- Número médio de habitantes por domicílio obtido a partir do Censo do IBGE;

- Área máxima construída por lote obtida a partir da área do lote e aplicação do coeficiente de aproveitamento de cada zona;

- Área máxima construída por lote residencial obtida a partir da área anterior, aplicada à taxa de uso residencial por zona;

- Número de Domicílios por Lote obtido a partir da área máxima construída por lote pela área da unidade domiciliar média.

- Número máximo de habitantes por lote obtido a partir do número de unidades residenciais por lote, multiplicado pelo número de habitantes por unidade

- Densidade demográfica máxima por setor, obtida através da multiplicação do número de habitantes por lote pelo número de lotes na zona e dividida pela área líquida da zona. Como cada bairro contém uma ou mais zonas urbanas, a densidade máxima final do bairro será ponderal, estabelecendo o peso proporcional à área de cada zona para se estabelecer a densidade máxima média do setor. 


\section{APTIDÃO URBANA AOS INSTRUMENTOS DO ESTATUTO DA CIDADE: PERSPECTIVAS METODOLÓGICAS}

A razão entre a densidade máxima do bairro (cenário de ocupação) e a densidade existente gera o Indicador de Densidade Demográfica Ponderal de cada bairro urbano.

\subsection{2. Índice de Pavimentação}

Este índice identifica a proporção do sistema viário em relação às áreas dos setores, descontados o patrimônio público, os equipamentos, áreas verdes e de preservação permanente. Analisado em conjugação à densidade demográfica existente permite indicar a maior ou menor utilização do sistema viário.

\subsection{3. Índice de Equipamentação Urbana}

Considera a existência das diferentes categorias de equipamentos conforme classificação exemplar a seguir: ${ }^{3}$

- Equipamentos da Área Social

- Equipamentos de Educação

- Equipamentos de Saúde

- Equipamentos de Esporte e Lazer

- Equipamentos de Cultura

- Equipamentos de Segurança Pública

Essa classificação varia de acordo com cada cidade e o elenco de equipamentos ali existentes. Apesar das especificidades de cada equipamento urbano, para efeito da presente simulação é considerada a soma dos equipamentos existentes no bairro ou setor urbano, dividida pela população do mesmo, o que permite a geração do indicador em pauta. Se houver a disponibilidade de maiores informações sobre os equipamentos, como capacidade de atendimento, dentre outras, este índice poderá ser depurado, estabelecendo pesos relativos a cada equipamento.

No caso da localização de equipamentos limítrofes a duas zonas, é utilizado para quantificação, meio equipamento por zona.

\footnotetext{
${ }^{3}$ A classificação dos equipamentos urbanos é estudada há muito tempo por diversos autores como FERRARI (1976) e RIGOTTI (1966).
} 


\section{APTIDÃO URBANA AOS INSTRUMENTOS DO ESTATUTO DA CIDADE: PERSPECTIVAS METODOLÓGICAS}

4.1.4. Índice de Áreas Institucionais (Patrimônio Público)

Este índice é obtido através da densidade de áreas institucionais: a razão entre o somatório das áreas institucionais medidas através dos lotes e a área líquida do bairro. Este índice indicará também a aptidão para a implantação de áreas institucionais no bairro e a necessidade de maior índice de pavimentação em função da acessibilidade a estes equipamentos. Adicionalmente indica o volume do investimento público no bairro, associando-o aos demais investimentos.

\subsection{5. Índice de Desconformidade Fundiária}

A desconformidade fundiária é aqui obtida através da razão entre a área dos loteamentos irregulares e/ou clandestinos e a área de loteamentos aprovados.

\subsection{6. Índice de Vulnerabilidade Urbana}

Este índice é obtido através da razão entre as áreas de risco, com problemas de drenagem, áreas com afloramento do lençol freático, voçorocas, áreas sujeitas à inundação e outros riscos, áreas de nascentes e fundos de vale e as áreas brutas dos setores.

\subsection{Classificação dos índices}

Os índices são relativizados, para efeito de análise, de acordo com o Quadro 2. O maior índice em cada categoria é igual a 1 (um).

\begin{tabular}{|l|l|l|}
\hline Classificação & Intervalo & Legenda \\
\hline Baixo/médio & $0-0,7$ & \\
\hline Alto & $0,71-1$ & \\
\hline
\end{tabular}

Quadro 2: Classificação dos Índices

Este intervalo foi arbitrado em analogia com o intervalo adotado pelo Atlas de Desenvolvimento Humano publicado pelo IBGE (2012), cuja régua classificatória é a seguinte: 


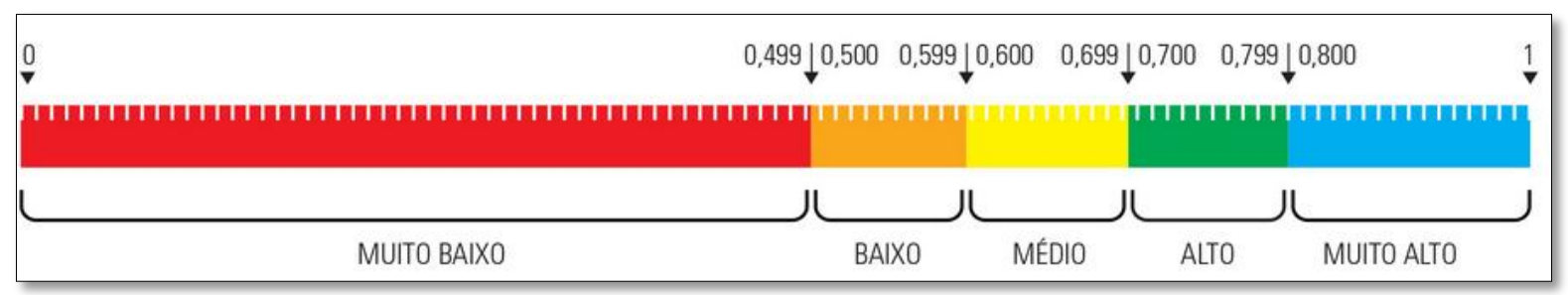

Figura 1: Régua de classificação do IDH.

Fonte: Atlas do Desenvolvimento Humano. IBGE, 2001.

Cada índice é classificado, para cada setor, em Baixo/Médio ou Alto, representados respectivamente nas cores laranja e rosa, tomando como referência para o maior índice o valor igual a 1 (um), ou seja, os índices tornam-se relativos, conforme explanado a seguir.

\subsection{1. Índice Relativo}

O índice relativo visa relativizar o raciocínio de Densidade Demográfica Ponderal em função das características intrínsecas de cada cidade, aproximando-se desta forma, à realidade da densidade de cada uma delas. É o valor encontrado a partir do cálculo, que atribui o valor 1(um) ao maior índice encontrado em cada bairro ou setor urbano.

\section{1 = VALOR MÁXIMO DENTRE OS SETORES}

Por exemplo, se o maior índice Densidade Demográfica Ponderal encontrado entre os setores urbanos é 0,846 , estabelece-se a relação, $0,846=1$, e os demais índices de Densidade Ponderal relativos a 1, conforme Quadro 3, abaixo.

\begin{tabular}{|c|c|}
\hline Índice Real & Índice Relativo \\
\hline 0,350 & 0,407 \\
\hline 0,846 & 1,000 \\
\hline 0,660 & 0,767 \\
\hline
\end{tabular}

Quadro 3: Cálculo do Índice Relativo

O Sistema de Gestão da Aptidão aqui sugerido, deve ser criado para acompanhamento da dinâmica urbana quanto à sua aptidão à aplicação dos instrumentos do Estatuto da Cidade, contendo ferramentas através das quais seja possível calcular e classificar os índices relativos, numa consulta rápida.

A seguir, é sistematizada a relação dos índices relativizados por setor.

a) Índice de densidade demográfica ponderal;

b) Índice de pavimentação; 


\section{APTIDÃO URBANA AOS INSTRUMENTOS DO ESTATUTO DA CIDADE: PERSPECTIVAS METODOLÓGICAS}

c) Índice de equipamentação urbana;

d) Índice de áreas institucionais;

e) Índice de desconformidade fundiária;

f) Índice de vulnerabilidade urbana.

No Quadro 4, a seguir, consta a Relação dos Índices relativizados por setor.

\begin{tabular}{|l|l|l|l|l|l|l|}
\hline \multirow{2}{*}{ Setores Índices } & \multicolumn{7}{|c|}{ ÍNDICES RELATIVOS } \\
\cline { 2 - 7 } & a & b & c & d & e & f \\
\hline 1. & 0,129 & 0,887 & 0,000 & 0,310 & & 0,000 \\
\hline 2. & 0,799 & 1,000 & 0,084 & 0,000 & & 0,000 \\
\hline 3. & 0,171 & 1,000 & 0,049 & 0,003 & & 0,000 \\
\hline 4. & 0,000 & 0,903 & 0,007 & 0,026 & & 0,046 \\
\hline 5. & 0,162 & 1,000 & 0,084 & 0,202 & & 0,000 \\
\hline
\end{tabular}

Legenda:

Índice relativo: o índice maior encontrado num dado bairro assume o valor $=1$ Índice baixo - $<0,7$ proporcional ao maior índice encontrado Índice alto - > 0,71 proporcional ao maior índice encontrado

Desconsiderada a análise por não conter o índice

Quadro 4: Índices Relativos por bairro ou setor

Fonte: As autoras. Atribuição hipotética de características de setores

Ressalta-se que os índices aferidos por setor são hipotéticos e o caráter das Aptidões assim obtido tem objetivo demonstrativo de uma proposta metodológica.

\subsection{Correlação entre os indicadores e os instrumentos}

Para estabelecimento dos Indicadores em sua correlação com os Instrumentos, foi gerado o Quadro 5, conforme critério de pertinência, discutido anteriormente no item 4. Este quadro é o resultado da análise dos objetivos de cada instrumento em relação às características dos indicadores, identificando o maior ou menor grau de relação de cada indicador ao instrumento analisado.

Para se chegar à aptidão dos setores, é necessário realizar a comparação entre os Indicadores por Setor (Quadro 4), e a relação Indicadores/Instrumentos (Quadro 5). Os indicadores com relação Alta ou Baixa são exigidos para a aplicação do instrumento. 


\section{METODOLÓGICAS}

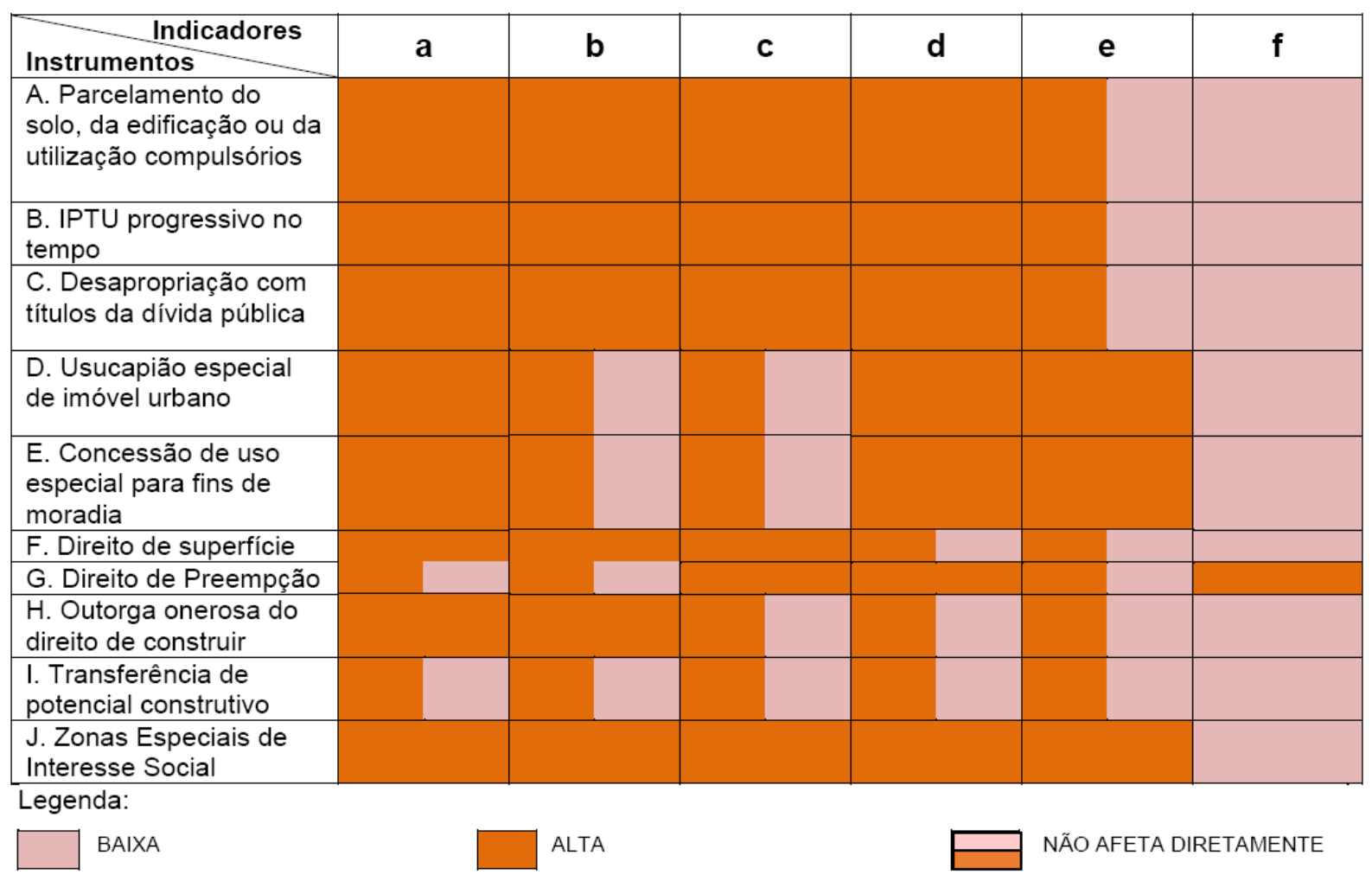

Quadro 5: Correlação entre os Indicadores e os Instrumentos

Fonte: As autoras. Atribuição hipotética de características de setores

\subsection{Análise de conformidades e desconformidades}

Hipoteticamente, no caso de não ser possível a obtenção de todos os dados necessários para a relação Indicador/Instrumento, pois se sabe que, frequentemente, as cidades brasileiras não contam com muitos dados e informações sobre seus territórios, pode-se atribuir aos índices zerados, a condição de "Desconformidade", quando fazem parte de um pré-requisito do instrumento. No caso de ser indiferente como pré-requisito, atribui-se a condição de "Conformidade".

A adoção desta condição é uma estratégia de apoio à comparação entre o Quadro 4 e o Erro! Fonte de referência não encontrada. por bairro ou setor, onde utilizam-se as condições abaixo que estabelecem a correlação da Aptidão com a frequência das Conformidades (C) e Desconformidades (D), dos 6 Indicadores, de acordo com a seguinte lógica de equivalência:

- 4 C e 2 D = Aptidão Alta $(A)$

- $5 \mathrm{C}$ e $1 \mathrm{D}=$ Aptidão Alta $(\mathrm{A})$

- 3 C e 3 D = Aptidão Média (M) 


\section{APTIDÃO URBANA AOS INSTRUMENTOS DO ESTATUTO DA CIDADE: PERSPECTIVAS METODOLÓGICAS}

- 2 C e 4 D = Aptidão Baixa (B)

- 1 C e 5 D = Aptidão Baixa (B)

A situação de "Conformidade" significa, por exemplo, na relação do Instrumento A com o Indicador 1, se o Indicador 1 é Alto, ele está numa situação de conformidade em relação ao pré-requisito do Instrumento A (Quadro 4), pois ele requer os Indicadores: $a, b, c$ e d, altos, sendo o Indicador $f$, indiferente, e o indicador g, baixo.

O mesmo raciocínio se aplica à situação de "Desconformidade". Por exemplo, quando o Indicador "e", dos exemplos seguir, é zerado para todos os setores (Quadro 4) e no Erro! Fonte de referência não encontrada., onde recebe a condição de correlação indiferente, para os instrumentos $A, B, C, F, G, H$ e J é de Conformidade, e de Desconformidade para os instrumentos D, E, I, K, onde a correlação é alta.

$\mathrm{Da}$ análise das conformidades e desconformidades entre os índices por bairro e os pré-requisitos dos instrumentos, identificam-se as Aptidões, Baixa, Media ou Alta de cada bairro por instrumento.

A seguir aplica-se a metodologia descrita para identificação das Aptidões em um setor hipotético.

\begin{tabular}{|c|c|c|c|c|c|c|c|}
\hline Índices & a & b & C & d & e & $f$ & Aptidão \\
\hline Instrumentos & & & & & & & \\
\hline A. & D & C & D & D & C & D & B \\
\hline B. & D & C & D & D & C & D & B \\
\hline C. & D & C & D & D & C & D & B \\
\hline D. & D & C & C & D & D & D & B \\
\hline E. & D & C & C & D & D & D & B \\
\hline F. & D & C & D & C & C & D & M \\
\hline G. & C & C & D & D & C & D & M \\
\hline H. & D & C & C & C & C & D & A \\
\hline I. & C & C & D & D & D & D & B \\
\hline J. & C & C & C & C & C & D & A \\
\hline K. & D & C & D & D & D & D & B \\
\hline
\end{tabular}

Legenda BAIXA
MÉDIA
ALTA

Quadro 6: Conformidade X Aptidão

Fonte: As autoras. Atribuição hipotética de características de bairros ou setores 


\section{APTIDÃO URBANA AOS INSTRUMENTOS DO ESTATUTO DA CIDADE: PERSPECTIVAS METODOLÓGICAS}

Esta metodologia é um instrumento de apoio à decisão dos gestores municipais quanto à seleção dos setores mais aptos à implantação dos Instrumentos do Estatuto da Cidade. Ressalte-se o caráter flexível da mesma em relação às variáveis que compõem os Indicadores, que devem ser adequadas a cada cidade.

\section{CONSIDERAÇÕES FINAIS}

Sabe-se que cada instrumento contido na Lei do Plano Diretor é genericamente aplicável a todos os setores urbanos, com exceção daqueles que já tiverem sido regulamentados para áreas especificas, definidas aprioristicamente.

A aplicação dos instrumentos deve ser progressiva, na medida da identificação da sua tempestividade, sendo que a seleção dos instrumentos prioritários é feita em função das características de cada setor urbano. Esta seleção obedece a critérios oriundos da relação entre Instrumentos/Indicadores relativos ao setor, sua compatibilidade e sinergia com seus objetivos advindos do Estatuto da Cidade.

Apesar desta metodologia ter partido da análise de três planos diretores, esta análise se restringiu a compatibilizar os dados e informações utilizadas para a constituição dos indicadores, àquelas usuais encontradas nos planos diretores analisados. Não se trata portanto, de uma aplicação real, mas sim de uma abstração metodológica baseada em dados reais existentes nas cidades estudadas.

As tabelas de aptidões dos setores definem suas aptidões para a aplicação prioritária dos Instrumentos da Política Urbana, pois retratam as características urbanas num determinado momento. É recomendável criar um Sistema de Gerenciamento das Aptidões, para monitoramento das variáveis que compõem os Indicadores, atualizando-os em conformidade com os dados específicos por setor, que refletem as modificações advindas da dinâmica urbana quanto ao uso e ocupação do solo, a implantação de infraestruturas, equipamentos e demais variáveis que compõem os indicadores.

Este sistema em ambiente SIG- Sistema de Informação Geográfica, permite o acompanhamento das transformações urbanas e são úteis para outras aplicações cujas variáveis possam se rebater sobre o território, tais como a revisão da 


\section{APTIDÃO URBANA AOS INSTRUMENTOS DO ESTATUTO DA CIDADE: PERSPECTIVAS METODOLÓGICAS}

legislação de uso e ocupação do solo, a seleção do melhor lugar para a implantação de equipamentos, dentre inúmeros outras.

Salienta-se que esta metodologia está baseada na sistematização das condições urbanas de cada bairro ou setor urbano, e respeita, portanto, as características de cada cidade para a definição dos indicadores. Caso haja maior disponibilidade de dados, os indicadores podem e devem ser revistos à luz destes dados. Um exemplo é a substituição do Índice de Pavimentação por índice de Infraestrutura, caso existam mapeamentos da mesma.

Acrescente-se que esta metodologia deve considerar também, o que constata Magalhães (2012, p.1), "as cidades não se congelam. Elas têm vida - e se modificam conforme os valores das gerações. Aí reside a condição que as tornam a maior obra da cultura." Trata-se do conceito do palimpsesto, onde a cidade se reescreve a cada dia, numa dinâmica de transformação advinda das relações sócioculturais, que devem prevalecer na construção do projeto de cidade necessária para um futuro sustentável.

\section{REFERÊNCIAS}

BRASIL. Lei Federal no 10.257. Estatuto da Cidade. Brasília, DF, publicado em 10 de julho de 2001.

BRASIL. Constituição (1988). Constituição da República Federativa do Brasil. Brasília, DF: Senado Federal, publicado em 05 de outubro de 1988.

FERRARI, C. Curso de planejamento municipal integrado. São Paulo: Pioneira, 1979, p.565-625.

FRANÇA, S. L. A. Grupo de artigo: participação e poder público - A participação popular nos planos diretores municipais: uma estratégia de gestão democrática. 2006. $\quad$ p. 9 . Consultado em: <http://gestaocompartilhada.pbh.gov.br/sites/gestaocompartilhada.pbh.gov.br/files/bi blioteca/arquivos/planos_diretores_e_participacao_popular.pdf $>$. Acesso em: 02 de janeiro de 2014. 


\section{APTIDÃO URBANA AOS INSTRUMENTOS DO ESTATUTO DA CIDADE: PERSPECTIVAS METODOLÓGICAS}

HONORATO, R. O direito público a espaços dignos. Eleições municipais renovam expectativa de melhor gestão das cidades brasileiras. Minha Cidade, São Paulo, ano 13, n. 149.06, Vitruvius, dez. 2012. Consultado em: <http://www.vitruvius.com.br/revistas/read/minhacidade/13.149/4599>. Acesso em: 02 de janeiro de 2014.

IBGE. INSTITUTO BRASILEIRO DE GEOGRAFIA E ESTATÍSTICA. Censo 2010. Consultado em: <http://www.ibge.gov.br/home/estatistica/populacao/Censo2010/ default.shtm>. Acesso em: 02 de janeiro de 2014.

JANOT, L. F. Uma luz no fim do túnel. Minha Cidade, São Paulo, ano 13, n. 149.03, Vitruvius, dez. 2012. Consultado em: <http://www.vitruvius.com.br/revistas/read/minhacidade/13.149/4620>. Acesso em: 02 de janeiro de 2014.

LEXINKON EDITORA LTDA Dicionário CALDAS AULETE, 2004. Consultado em: www.aulete.uol.com.br. Acesso em: 02 de janeiro de 2014.

MAGALHÃES, Sérgio. A cultura do convívio. Minha Cidade, São Paulo, ano 13, n. 149.05, Vitruvius, dez. 2012. Consultado em: <http://www.vitruvius.com.br/revistas/read/minhacidade/13.149/4533>. Acesso em: 02 de janeiro de 2014.

PEREIRA DA SILVA, J. M.; TRÍPOLI MAGALHÃES, N. C. Contradições da Região Metropolitana de Campinas. Delimitação das ZEIS e a localização dos investimentos públicos em habitação de interesse social. Arquitextos, São Paulo, ano 14, n. 158.00, Vitruvius, ago. 2013. Consultado em: <http://www.vitruvius.com.br/revistas/read/arquitextos/14.158/4821>. Acesso em: 02 de janeiro de 2014.

RIGOTTI, G. Urbanistica: La Tecnica, Talleres Gra'ficos Ibero-Americanos, S.A. Provenza ,86, Barcelona, 1966.

SANTOS JUNIOR, O. A.; MONTANDON, D. T. In: (orgs.) Os planos diretores municipais pós Estatuto da Cidade: balanço crítico e perspectivas. Rio de Janeiro: Letra Capital, 2011. p. 33-36.

TESE Tecnologia em Sistemas Espaciais Ltda. Plano Diretor de Uberlândia. Relatório Técnico, março de 2006.

TESE Tecnologia em Sistemas Espaciais Ltda. Plano Diretor de Umuarama. Relatório Técnico, outubro 2005. 
TESE Tecnologia em Sistemas Espaciais Ltda. Plano Diretor de São Miguel do Iguaçu. Relatório Técnico, setembro 2002.

ULTRAMARI, C.; REZENDE, D. A. Mudanças e continuidades na gestão urbana brasileira. REVISTA PARANAENSE DE DESENVOLVIMENTO, Curitiba, n.111, p.19-28, jul./dez. 2006.

VILLAÇA, F. As Ilusões do Plano Diretor. São Paulo, Edição do autor, 2005. Livro em arquivo.pdf. Consultado em:<www.usp.br/fau/galeria/paginas/index.html>. Acesso em: 02 de janeiro de 2014. 